\title{
Neuropathic Pain in Multiple Sclerosis-Current Therapeutic Intervention and Future Treatment Perspectives
}

\author{
KAYLA L. MURPHY • JOHN R. BETHEA • ROMAN FISCHER \\ Department of Biology, Drexel University, Philadelphia, PA, USA \\ Author for correspondence: Roman Fischer, Department of Biology, Drexel \\ University, 3245 Chestnut Street, Philadelphia, PA 19104, USA. E-mail: \\ rf428@drexel.edu \\ Doi: http://dx.doi.org/10.15586/codon.multiplesclerosis.2017.ch4
}

\begin{abstract}
Chronic pain is defined as any consistent pain lasting more than 12 weeks; chronic pain afflicts $25 \%$ of the world's population. The most common form of chronic pain is chronic neuropathic pain, which affects around $8 \%$ of the general population and is defined as pain that is initiated or caused by a primary lesion or dysfunction of the nervous system. Neuropathic pain is commonly associated with a variety of neurodegenerative, metabolic, and autoimmune diseases. In multiple sclerosis (MS), chronic neuropathic pain is one of the most frequent symptoms that dramatically reduces the quality of life of MS patients. Current treatment strategies include antidepressants, anticonvulsants, and cannabinoid drugs. However, the efficacy of these drugs varies between patients. Besides providing only insufficient relief of pain, these drugs also lead to severe side effects. Therefore, there is an unmet medical need to identify novel drug targets, which may lead to the development of novel therapeutics with enhanced tolerability profiles and efficacy for the management of MS-associated chronic neuropathic pain.
\end{abstract}

\footnotetext{
In: Multiple Sclerosis: Perspectives in Treatment and Pathogenesis. Ian S. Zagon and Patricia J. McLaughlin (Editors), Codon Publications, Brisbane, Australia. ISBN: 978-0-9944381-3-3; Doi: http://dx.doi.org/10.15586/codon.multiplesclerosis.2017
}

Copyright: The Authors.

Licence: This open access article is licenced under Creative Commons Attribution 4.0 International (CC BY-NC 4.0). https://creativecommons.org/licenses/by-nc/4.0/ 
Key words: Allodynia; Experimental autoimmune encephalomyelitis; Inflammation; Multiple sclerosis; Neuropathic pain

\section{Introduction}

Pain is an unpleasant sensation that is often provoked by a noxious stimulus and can result in tissue damage. However, it also encourages a person to withdraw from damaging situations or to protect an injured body part while it heals and is therefore an essential component of the protective response of the human body. Pain is often a transient sensation that lasts until the noxious pain stimulus is detracted or the underlying damage or pathology has healed, but some forms of pain may become chronic lasting over months or years, even after the initial injury has healed. Different forms of pain can be classified by their underlying mechanism (1). Nociceptive pain is caused by a noxious stimulus, resulting in damage to body tissue and is usually described as a sharp, aching, or throbbing pain. Inflammatory pain occurs in response to the release of inflammatory mediators from injured tissue, for example, during autoimmune diseases such as arthritis or inflammatory bowel disease. The most common form of chronic pain is chronic neuropathic pain, which is defined as a chronic pain condition that is caused by a lesion or disease of the somatosensory nervous system that is not mediated via a noxious stimulus (2). Chronic neuropathic pain is frequently present in a large number of medical conditions and can result from a variety of injuries to the peripheral nervous system (PNS) or the central nervous system (CNS). Furthermore, chronic neuropathic pain may result as a consequence of a variety of conditions such as cancer, metabolic diseases, autoimmune disorders, and neurodegenerative diseases, including multiple sclerosis (MS). Often, patients with chronic neuropathic pain are more susceptible to pain and experience severe pain. These symptoms are termed "hyperalgesia," which is defined as an increased sensitivity to pain, and "allodynia," a condition wherein typically nonpainful stimuli lead to painsensation (3). Importantly, neuropathic pain is not only mediated by a sensory component but also comprises perception, cognition, and higher brain center processing, making it a dynamic multidimensional experience (4).

\section{Neuropathic Pain}

\section{ETIOLOGY AND EPIDEMIOLOGY}

Chronic pain has been defined as a pain lasting more than 12 weeks, and as irregular somatosensory processing in the PNS or CNS that is sustained beyond the normally expected time course relative to the stimulus (4). Due to its high prevalence, chronic pain is currently the most common human health problem, affecting more than $25 \%$ of the world's population, and is rising in incidence as the population ages (5). Chronic neuropathic pain affects around $8 \%$ of the general population (6) and is caused by many disparate sources such as cancer, autoimmune 


\section{TABLE 1 Overview of disease-associated chronic neuropathic pain}

\begin{tabular}{|c|c|c|}
\hline Disease & Prevalence of pain & Pain symptoms \\
\hline Multiple sclerosis & $50-86 \%(8,9)$ & $\begin{array}{l}\text { Extremity pain, trigeminal neuralgia, } \\
\text { back pain, headaches }\end{array}$ \\
\hline Parkinson's disease & $40-60 \%(10,11)$ & $\begin{array}{l}\text { Musculoskeletal pain, dystonia, central } \\
\text { neuropathic pain }\end{array}$ \\
\hline Alzheimer's disease & 57\% (12) & Musculoskeletal pain \\
\hline Diabetes & $64 \%(13)$ & $\begin{array}{l}\text { Painful neuropathy, mixed pain } \\
\text { symptoms }\end{array}$ \\
\hline Cancer & $\begin{array}{l}\sim 78 \% \text { (direct tumor involvement) (14) } \\
\sim 90 \% \text { of chemotherapy patients (15) }\end{array}$ & $\begin{array}{l}\text { Plexopathies, } \\
\text { Painful cranial neuralgias, sensory } \\
\text { neuropathy }\end{array}$ \\
\hline
\end{tabular}

and metabolic diseases, and CNS injuries and neurodegenerative diseases (7), with prevalence ranging from 40 to $90 \%$ depending on the disease (8) (Table 1). Chronic neuropathic pain negatively affects a person's level of functioning and quality of life. Its resistance to available pain therapies means there is an unmet medical need for the development of more efficacious therapeutics for chronic neuropathic pain.

\section{DIAGNOSIS}

Physicians typically assess a patient's pain through medical history and conduct a physical exam, but beyond that tests are subjective (16). Historically, neuropathic pain has often been disregarded by physicians, and patients have been labeled as hypersensitive. However, recent research has shown that neuropathic pain can be the underlying cause of a variety of secondary symptoms that severely affect the quality of life of patients $(4,8)$. There is still a need for greater standardization by which physicians can diagnose neuropathic pain, but newly proposed screening questionnaires and diagnostic procedures such as quantitative sensory testing, painrelated evoked potentials, and skin biopsy have advanced the mechanistic approach to pain management, leading to the development of the so-called sensory profiles (17). Physical and neurological examinations are typically done to assess neuropathic pain, but there are no defined diagnostic guidelines that are universally used among physicians. Only recently, updated criteria were developed by which physicians can more effectively and universally diagnose neuropathic pain (18). These criteria are based on a three-level grading system. For the first level of assessing possible neuropathic pain, patients need to show a history of relevant neurological lesion or disease, and the pain distribution reported by the patient needs to be consistent with the suspected lesion or disease. The second level of certainty to diagnose possible neuropathic pain involves a physical examination of sensory function to ensure that pain is associated with sensory signs in the same neuroanatomically plausible distribution. The third level of certainty to establish definite neuropathic pain requires the use of diagnostic tests to confirm the disease or lesion of the somatosensory nervous system that explains the pain (18). 


\section{SYMPTOMS}

Individuals that suffer from neuropathic pain exhibit stimulus-independent persistent pain that is characterized by abnormal sensations or hypersensitivity in the affected area and often is combined with, or is next to, areas of sensory deficits $(19,20)$. Patients often describe the pain as a burning and/or stabbing sensation (21). Neuropathic pain symptoms include tactile or thermal hypoesthesia (reduced sensation to nonpainful stimuli), hypoalgesia (reduced sensation to painful stimuli), loss of sensation, paraesthesia (abnormal sensations such as skin crawling or tingling), paroxysmal pain (e.g., shooting, electric shock-like sensations), spontaneous ongoing pain (not induced by stimulus like, for example, burning sensation), and evoked pain (i.e., stimulus-induced pain), the last of which includes hyperalgesia (increased sensitivity to painful stimuli) and allodynia (perception of innocuous/nonpainful stimuli as painful) $(19,20)$. In addition to sensations of pain, abnormal sensations have also been reported such as crawling, numbness, itching, and tingling (22). Furthermore, pain can be triggered by typically nonpainful stimuli such as being lightly touched and hot or cold temperatures (22). Secondary symptoms that commonly accompany neuropathic pain include depression, sleep disturbance, fatigue, and decreased physical and mental functioning $(23,24)$.

\section{GENDER DIFFERENCES}

Interestingly, women are affected more often by chronic pain than men (25). Certain chronic pain syndromes occur only in women, for example, endometriosisrelated pain, vulvodynia, and menstrual pain (5). Furthermore, several chronic pain syndromes such as chronic fatigue syndrome, fibromyalgia, interstitial cystitis, temporomandibular disorder, headache, migraine, lower back pain and knee pain (mostly osteoarthritis) are more common in women (5). Similarly, chronic neuropathic pain is also more prevalent in females $(26,27)$, indicating that women are at a greater risk of developing neuropathic pain than men (8). The predominance of females with chronic pain might depend on several indications (5). First, women seek health care services more often than men for both painful and nonpainful disorders, and might be more willing to report pain than men, leading to a higher percentage of women represented in epidemiological studies (28). In addition, multiple reports suggest that pain levels within chronic pain conditions are increased in women compared to men (5). Altogether, these data suggest that women might be more susceptible to chronic pain, and/or have a lower pain tolerance, compared to men. Women may have an increased risk of developing conditions that feature pain as a syndrome, ultimately leading to higher percentages of women crossing the threshold at which the pain experienced rises to the level of a diagnosed "pain syndrome" (5).

\section{AFFECTIVE DISORDER-DEPRESSION}

Depression, one of the most common psychiatric disorders, is a mood disorder that causes a persistent feeling of sadness and loss of interest, along with at least four of the following symptoms for a duration of no less than 2 weeks: appetite/ weight disturbance, sleep disturbance, psychomotor change, loss of energy, 
worthlessness/guilt, concentration difficulties/indecisiveness, and/or thoughts of death or suicide $(4,29)$. Depression is a common comorbid psychiatric diagnosis encountered in patients diagnosed with chronic neuropathic pain and affects the majority (57\%) of chronic neuropathic pain patients, thereby intensifying the patient's disability and impairment as well as the challenge of successful treatment (4). In the general population, depression ranges from 4 to $8 \%$ (4). In contrast, patients diagnosed with chronic pain have a two to five times increased risk of developing depression compared to the general population $(30,31)$. However, since pain and depression are often comorbid, the assessment of depression in the presence of pain is complicated due to shared features between the two syndromes, such as fatigue and sleep disturbance (32).

\section{Multiple Sclerosis-Induced Neuropathic Pain}

\section{PATHOPHYSIOLOGY OF MS-ASSOCIATED PAIN}

MS is a chronic inflammatory demyelinating disease of the CNS that leads to motor, sensory, and cognitive impairment, and is characterized by demyelinated lesions within the CNS (33). Chronic pain is one of the most frequent MS-associated symptoms that dramatically reduces the quality of life of MS patients and treatment options for chronic neuropathic pain are very limited and often not very effective $(20,34,35)$. Estimates on the prevalence of pain in MS vary considerably depending on the population of patients sampled, the definition of MS-associated pain used, and the survey methods employed. Pain prevalence in MS ranges from $25-90 \%(8,36,37)$, depending upon the assessment protocols used and the definition of pain being applied (34). MS-induced chronic neuropathic pain is typically associated with significant MS-related disability and depression (38) and pain syndromes can be divided into primary pain caused directly by demyelination, neuroinflammation, and/or axonal damage in the CNS from disease, or into secondary pain due to an indirect consequence of the CNS lesion $(8,39)$. Interestingly, recent imaging studies showed that demyelinating lesions are most commonly reported in the brainstem and less commonly in the spinal cord. Further, most studies reported associations between the localization of lesions and pain (40). The clinical presentation of MS-associated pain can be categorized as stimulus-independent or dependent $(41,42)$. Whereas stimulus-independent pain includes persistent or paroxysmal pain, evoked pain is characterized by hyperalgesia and allodynia $(41,42)$.

MS patients can suffer from nociceptive pain, such as pain resulting from musculoskeletal problems, neuropathic pain, or a mixed nociceptive/neuropathic pain (e.g., tonic painful spasms or spasticity) (17). Chronic neuropathic pain is more persistent in nature and is one of the most commonly distressing symptoms experienced by patients even in the early stages of the disease $(8,43)$. MS patients can experience a wide range of neuropathic pain symptoms (Table 2). The most common MS-associated chronic neuropathic pain conditions are ongoing dysaesthetic pain in the lower extremities, paroxysmal pain, which can be divided into Lhermitte's phenomenon and trigeminal neuralgia, as well as thermal and mechanical sensory abnormalities $(8,17,34)$. Other forms of neurogenic pain, including 


\section{TABLE 2 Overview of chronic neuropathic pain conditions in $\mathrm{MS}$}

\begin{tabular}{|c|c|c|}
\hline Type of pain & Description & Prevalence \\
\hline $\begin{array}{l}\text { Dysaesthetic extremity } \\
\text { pain }\end{array}$ & $\begin{array}{l}\text { Burning, tingling, or aching predominately } \\
\text { in lower extremities }\end{array}$ & $\begin{array}{l}\text { 12-28\% } \\
\quad \text { (life-time prevalence) }\end{array}$ \\
\hline \multirow[t]{2}{*}{ Paroxysmal pain } & $\begin{array}{l}\text { Lhermitte's phenomenon-shock-like } \\
\text { sensation traveling from the back } \\
\text { toward the lower limbs }\end{array}$ & $\begin{array}{l}\text { L'hermitte's phenomenon: } \\
\qquad 9-41 \%\end{array}$ \\
\hline & $\begin{array}{l}\text { Trigeminal neuralgia-sudden, severe, } \\
\text { brief stabbing reoccurring episodes of } \\
\text { pain in one or more branches of the } \\
\text { trigeminal nerve }\end{array}$ & $\begin{array}{l}\text { Trigeminal neuralgia: } \\
2-6.3 \%\end{array}$ \\
\hline Migraine & $\begin{array}{l}\text { Long-lasting headaches, possibly due to } \\
\text { brain lesions }\end{array}$ & $34 \%$ \\
\hline Spasticity pain & $\begin{array}{l}\text { Excessive muscular work and mechanical } \\
\text { muscle pain }\end{array}$ & $<50 \%$ \\
\hline Painful tonic spasms & $\begin{array}{l}\text { Spasmodic muscle contractions, ischemic } \\
\text { muscle pain }\end{array}$ & $6-11 \%$ \\
\hline
\end{tabular}

migraine with or without aura and tension-type headache, seem to be more prevalent in MS patients than in the general population (44). Dysaesthetic extremity pain is often characterized as a continuous burning, tingling, or aching dysaesthesia, predominantly in the legs and feet that is often worse at night and can be exacerbated by physical activity $(8,34,39)$. In patients with MS, dysaesthetic extremity pain is the most commonly reported type of neuropathic pain, having a prevalence of $12-28 \%(45,46)$. Interestingly, MS patients with primary progressive or progressive-relapsing MS are more likely to suffer from dysaesthetic pain than patients with the relapsing-remitting disease form (45). L'hermitte's phenomenon is described as a transient, short-lasting paroxysmal electrical sensation that originates in the neck and spreads down to the lower limbs and is usually related to neck movement. Although this phenomenon is not exclusive to MS, it is frequently reported by patients with MS (45), with a prevalence ranging from 9 to $41 \%$ depending on the parameters of the study $(47,48)$. In most patients, the symptoms resolve within 4 to 6 weeks; however, they may recur occasionally, especially during MS exacerbations (48).

Trigeminal neuralgia (TN) is characterized by sudden, usually unilateral paroxysmal attacks of electric shock-like episodes of pain in specific facial or intraoral areas that affect one or more branches of the trigeminal nerve (49). The prevalence of trigeminal neuralgia in patients with MS ranges from 1 to $6.3 \%$, corresponding roughly to 20 times the prevalence in the general population $(8,41,50)$. Importantly, the incidence of MS-associated chronic pain is not correlated with disease severity (36). Further, several studies suggest that pain prevalence and severity are not strongly correlated with age, 
physical functioning, disease duration, or disease course (36). However, pain prevalence and severity of MS were found to strongly correlate with reduced social functioning and mental health, and pain severity was found to be significantly related to anxiety and depression, predominantly in women (36). Interestingly, the pathophysiology of trigeminal neuralgia (TN) in MS patients differs from TN in the general population and specifically involves CNS demyelination (51). Recent analyses revealed unique, focal diffusivity changes along the fifth cranial nerve in MS TN patients compared to TN patients or healthy controls. These MS patient-specific diffusivity changes are likely due to MS plaques at the regions proximal to the main sensory nucleus (52).

\section{SEX DIFFERENCES IN MULTIPLE SCLEROSIS AND ASSOCIATED PAIN}

Females are more often affected with MS than men, a phenomenon shared with several other autoimmune diseases. The prevalence and incidence of MS is twoto-three fold higher in females, compared with males (33). Similar sex differences were found for MS-associated pain. Whereas female MS patients experienced more severe pain than females in the general population, no difference in pain severity was found between male MS patients and men in the general population (36). Another study also suggested a sex difference in pain prevalence among MS patients, showing a higher female-to-male ratio among MS patients with pain compared to MS patients without pain (53). In contrast, some newer studies did not detect sex differences for pain prevalence in MS $(54,55)$. Altogether, there is evidence for sex differences in MS-associated pain; however, this has not been sufficiently addressed compared to the general sex differences on pain and, therefore, gender-dependent pain prevalence is still controversially discussed.

\section{Pathophysiological Insights from Experimental Autoimmune Encephalomyelitis Models}

In contrast to the wealth of research on the pathophysiology of neuropathic pain induced by peripheral nerve injury, only a limited amount of research on the pathophysiology of central or MS-associated neuropathic pain is available. In the field of MS, the majority of research on pain makes use of the rodent models of experimental autoimmune encephalomyelitis (EAE). EAE animals share many features observed in MS patients, such as pattern of the clinical disease course, histopathological CNS lesions characterized by perivascular cuffs with mononuclear cell infiltration, gliosis, demyelination and axonal damage (56). Furthermore, EAE animals mirror a lot of the pain reactions occurring in humans (34) and similar to clinical administration, pain-like behaviors in EAE mice can be ameliorated by anticonvulsant and antidepressant drugs $(34,57)$.

\section{NEURODEGENERATION AND DEMYELINATION}

Neurodegeneration and demyelination are common hallmarks of both MS and EAE (58) and lead to distinct mechanisms that may cause central neuropathic pain. 
A recent report shows that genetic ablation of oligodendrocytes rapidly triggers a pattern of sensory changes that lead to a nociceptive hypersensitivity phenotype that closely resembles central neuropathic pain. Interestingly, this occurred at a time point that preceded apparent demyelination and ataxia and coincided with early axonal pathology in the spinothalamic tract (59). This is in line with data showing that pain-like behaviors occur prior to infiltration of immune cells into the CNS and prior to the development of clinical motor signs in EAE rodents and human patients (57). Mechanistically, oligodendrocyte loss-dependent hyperalgesia and allodynia were not causally associated with microglial reaction or T-cell contributions, demonstrating that central neuropathic pain can be caused by oligodendrocyte death and axonal pathology in the absence of an innate or adaptive immune response (59).

\section{INFLAMMATION AND REACTIVE GLIOSIS}

Inflammatory cells and immune-like glial cells are important mediators of central sensitization and contribute to neuropathic pain symptoms (60). Interestingly, typical cellular substrates associated with pain processing and peripheral neuropathic pain, such as altered expression of sensory neuropeptides, do not appear to underlie changes in sensory function in EAE mice (57). In contrast, EAE mice showed a significant influx of T-cells and increased astrocyte and microglia/macrophage reactivity in the superficial dorsal horn of the spinal cord, an area associated with pain processing (57), suggesting that inflammation and reactive gliosis may be key mediators of allodynia in EAE animals. Indeed, activated glial cells can release pro-inflammatory cytokines, glutamate, and nitric oxide during reactive gliosis and may amplify neuronal hyperexcitability, leading to the development of neuropathic pain (60). In addition, pro-inflammatory cytokines were shown to play a pathogenic role in the development of neuropathic pain (61). Moreover, reactive gliosis and a significant increase in the expression of the inflammatory cytokines in the dorsal root ganglia of EAE animals correlates with the onset of neuropathic pain behaviors in EAE rodents (57). In line with the important role of inflammation for pain development, gene therapy with anti-inflammatory IL-10 in EAE animals improved motor and sensory function, prevented allodynia, and reduced glial activation in the lumbar spinal cord (62).

\section{Pharmacological Management of Neuropathic Pain}

\section{MANAGEMENT OF MULTIPLE SCLEROSIS-RELATED NEUROPATHIC PAIN}

Although some pain relief can be afforded by conventional pain medications, no current therapy provides more than 50\% pain relief in the clinic and large randomized and controlled clinical trials for MS-associated chronic neuropathic pain are lacking (34). Therefore, management recommendations for neuropathic pain in MS (Figure 1) tend to be generally guided by findings in other diseases, for example, spinal cord injury-induced chronic neuropathic pain or peripheral neuropathic pain syndrome (45). Since the primary affected brain regions and 
Anti-inflammatory drugs

Immune suppressive drugs

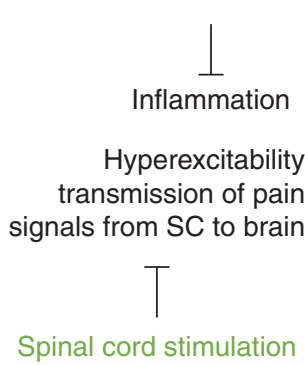

Serotonin \& norepinephrine reuptake

1 SSRIS

- TCAs \& SNRIS

Excessive release of neurotransmitter

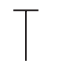

Natural and synthetic cannabinoid drugs

Excessive neuronal excitation excitatory cell death
Anticonvulsants NMDAR antagonists

Figure 1 Disruption of MS pain signals by different treatments. Signals in the CNS (brain and spinal cord) and the PNS contribute to the development of neuropathic pain. Different therapies interfere with pain signals (black) and can lead to the alleviation of neuropathic pain. Antidepressants (TCAs, SNRIs, and SSRIs) inhibit the reuptake of serotonin alone or serotonin and norepinephrine, the key neurotransmitters that are hypothesized to be involved in the modulation of neuropathic pain. Natural and synthetic cannabinoid drugs prevent the excessive release of neurotransmitters in the CNS. Anticonvulsants and NMDAR antagonists block excessive neuronal excitation that may lead to excitatory cell death. Spinal cord stimulation blocks hyperexcitability of neurons in the spinal cord and prevents transmission of pain signals from the spinal cord to the brain. Recently, antiinflammatory drugs were investigated that block inflammatory signaling associated with development of chronic pain.

neuromodulators are shared between chronic pain and depression, the same drugs often are used for both disorders (4). Temporary pain relief is often achieved through antidepressants and anticonvulsants. However, all these therapies have long-term complications and only a short-term efficacy that leaves patients with untreated and constant pain (4). Furthermore, in general chronic pain and in MS-associated chronic neuropathic pain in particular, the conventional analgesics only insufficiently relieve or do not relieve pain at all $(8,46)$. Adjuvant drugs such as the tricyclic antidepressants (TCAs), serotonin/norepinephrine reuptake inhibitors (SSRIs), and some anticonvulsants, for example, gabapentin or topical lidocaine are utilized as first-line drug therapy for alleviation of MS-associated neuropathic pain $(34,37,46)$. Opioid analgesics (e.g., morphine, oxycodone, methadone, and fentanyl) and tramadol (alone or in combination with a firstline agent) are generally regarded as second-line treatments $(34,63,64)$. Thirdline agents that may be used as second-line treatments in some circumstances include other antiepileptic drugs (e.g., carbamazepine, lamotrigine, oxcarbazepine, topiramate, and valproic acid), mexiletine (orally active lignocaine analogue), and topical capsaicin $(34,63,64)$.

\section{ANTIDEPRESSANTS}

Often antidepressants are used to treat pain; however, they differ in their efficacy. TCAs are the most studied and clinically used antidepressants for the treatment of neuropathic pain (65). They can be divided into two major groups: tertiary amines, for example, doxepin, imipramine, and amitriptyline, and secondary amines, for example, nortriptyline and desipramine (66). TCAs inhibit the reuptake of serotonin 
and norepinephrine, the key neurotransmitters that are hypothesized to be involved in the modulation of neuropathic pain at the synapse, and block alpha adrenergic, serotonergic, histaminic, and muscarinic receptors at the synapse $(32,66)$. Their activity differs according to their chemical structure, whereas the tertiary amines raise serotonin levels to a greater degree than norepinephrine, the secondary amines have more pronounced effects on norepinephrine $(32,66)$. Interestingly, the therapeutic effects on pain seem to be independent of the antidepressant effects of these drugs and may be achieved at lower doses compared to clinically effective doses used to treat depression $(32,66)$. Despite the efficacy of TCAs in pain treatment, their use is limited due to pronounced side effects (e.g., weight gain, anticholinergic effects, orthostatic hypotension, and cardiovascular effects) and a high risk of overdosing, potentially leading to the death of patients $(32,66)$.

Next-generation drugs include SSRIs that exert their therapeutic efficacy mainly by the inhibition of the reuptake of serotonin (32). However, the use of SSRIs for the treatment of neuropathic pain seems to be less effective than other antidepressants and the number of clinical studies is limited (67). Paroxetine and citalopram, for example, showed just a modest activity for pain management, whereas fluoxetine had no therapeutic activity on pain at all (65). This leads to the assumption that noradrenaline reuptake inhibition is the major underlying mechanism of the analgesic efficacy of TCAs. Positively, the side effects of SSRIs are generally mild, for example, increased risk of weight gain or sexual dysfunction (32).

A therapeutic that inhibits both serotonin and norepinephrine reuptake (SNRI) is venlafaxine. Interestingly, low doses mainly impact serotonin and high doses mainly affect norepinephrine (32). Case reports and empirical studies indicate that venlafaxine can be clinically used to treat neuropathic pain, and its efficacy is comparable to TCAs (65). In general, venlafaxine use may lead to increased blood pressure and has a discontinuation syndrome with abrupt cessation. However, in general, it leads to less severe side effects, and its use is safer compared with TCAs (32). Duloxetine, the only antidepressant approved by the US Food and Drug Administration for the treatment of neuropathic pain, inhibits both SNRI and may cause side effects such as nausea, somnolence, dizziness, and fatigue (32). Interestingly, a randomized double-blind, placebo-controlled clinical trial of duloxetine, in patients with spinal cord injury-induced chronic neuropathic pain, showed that although duloxetine significantly improved allodynia relative to placebo, pain intensity was not significantly reduced compared with placebo (68). Therefore, the efficacy for the relief of MS-associated chronic neuropathic pain is still unclear.

\section{ANTICONVULSANTS}

Anticonvulsants or antiepileptic drugs normally suppress the rapid and excessive excitation of neurons during seizures. The efficacy of anticonvulsants, for example, lamotrigine, levetiracetam, topiramate, and gabapentin for MS-associated chronic neuropathic pain relief has been investigated in small clinical trials $(69,70)$. However, each of these studies showed that the anticonvulsants either led to an incomplete pain relief or that the drug had a limited tolerance and had to be discontinued due to intolerable adverse effects (34). 
Carbamazepine is the most effective first-line treatment for MS-associated trigeminal neuralgia. However, due to its poor tolerance, with side effects including leg muscle weakness and micturition problems that can mimic MS relapses, treatment often has to be discontinued $(34,37,71)$. Oxcarbazepine, the keto derivative of carbamazepine, has a similar therapeutic efficacy like carbamazepine for treatment of trigeminal neuralgia but shows an improved tolerance compared to carbamazepine (72). In addition, anticonvulsants are often recommended to treat relentless pain due to L'hermitte's phenomenon (46). However, neither drug effectively relieved persistent painful symptoms associated with MS (73).

\section{CANNABINOID DRUGS}

Natural or synthetic cannabinoid drugs, which inhibit the function of the endocannabinoid system involved in pain sensation, and alter neurotransmitter release in the CNS (74), demonstrated therapeutic efficacy in relieving MS-associated chronic neuropathic pain. However, several treatment-related side effects were observed, such as dizziness, dry mouth, headache, tiredness or muscle weakness (75). In addition, probable cannabis misuse and the risks of developing acute psychosis have sidelined these drugs to second-line or thirdline medications to treat MS-associated chronic neuropathic pain (63).

\section{NEUROSTIMULATION}

A notable number of patients do not achieve sufficient pain relief with classical pharmacological medication alone. However, neurostimulation techniques, such as transcutaneous electrical nerve stimulation (TENS), peripheral nerve stimulation, nerve root stimulation (NRS), spinal cord stimulation (SCS), deep brain stimulation (DBS), epidural motor cortex stimulation (MCS), and repetitive transcranial magnetic stimulation (rTMS) show promise in treating chronic neuropathic pain (76). In particular, a recent case report and literature search showed that SCS, a stimulation method that directs mild electrical pulses to the spinal cord, and thereby inhibits pain transition from the spinal cord to the brain, was successfully used to alleviate MS-associated neuropathic pain (77). The exact mechanisms of SCS are not completely understood yet, but attenuated neuronal hyperexcitability was shown to contribute to its therapeutic effect (78).

\section{CURRENT AND FUTURE DEVELOPMENTS}

Next to conventional pain therapies using antidepressants and anticonvulsants, novel therapeutic approaches are currently being developed. Since MS is an inflammatory disease, most drugs used to treat MS-related motor symptoms target the inflammatory process. Interestingly, current research also identified the peripheral immune system as a relevant target for therapeutic intervention for pain. An important protein of peripheral inflammation is the mammalian target of rapamycin (mTOR), which has been implicated in behavioral hypersensitivity associated with neuropathy and pain (79). Administration of rapamycin, an 
inhibitor of mTOR, not only reversed clinical signs of EAE motor disease but also ameliorated pain in EAE animals (80). Most likely, the therapeutic effect of rapamycin in EAE is dependent on its immunosuppressive activity involving inhibition of effector T-cells, expansion of regulatory T-cells, and inhibition of glial cell activation $(80,81)$ - all processes shown to contribute to the pathology of MS-associated chronic neuropathic pain. In line with this, anti-inflammatory cytokine gene therapy reduced EAE disease course and prevented mechanical allodynia (62). In addition, fingolimod, an immune suppressive drug that reduces MS relapse rates and lesion frequency (82), has been shown to promote pain alleviation in animals with peripheral nerve injury-mediated pain conditions (83).

Next to immunosuppressive therapies, glutamate receptors are promising targets for MS pain therapy. The N-methyl-D-Aspartate (NMDA) receptor has been proposed as a primary target for the treatment of neuropathic pain, and several clinical trials show beneficial effects of NMDA receptor antagonists on pain relief (84). Glutamate homeostasis is altered in MS patients, with higher levels of glutamate or altered glutamate uptake in the CNS of MS patients $(85,86)$. These excessive glutamate concentrations can allow prolongation of calcium-permeable ionotropic glutamate receptor activation on neural and glial cells, ultimately leading to excitotoxic CNS tissue damage (87). Similarly, dysregulation of the glutamatergic system, caused by reduced glutamate transporter expression in spinal cords, has been implicated in abnormal pain sensitivity in EAE mice (88). Furthermore, administration of drugs that promote glutamate transporter activity has not only been shown to limit and improve clinical motor symptoms but also to significantly alleviate pain and normalize performance in cognitive assays in EAE rodents (88).

\section{Conclusion}

Patients with MS develop, among other ailments, chronic neuropathic pain. Unfortunately, there is a lack of adequate controlled trials in MS patients to assess the efficacy of established pain-relieving agents. Hence, treatment recommendations for MS-related pain largely rely on experience from other diseases with associated neuropathic pain. Currently, the number of medications for the treatment of MS-mediated chronic neuropathic pain is limited, and their use is often associated with severe adverse evets. Therefore, there is an urgent medical need to identify novel drug targets which may lead to the development of therapeutics with improved tolerability, low toxicity, and enhanced efficacy for the management of MS-associated chronic neuropathic pain. Some promising targets are mTOR, glutamate receptors and NMDAR (N-methyl-D-Aspartate receptor).

Acknowledgment: This work was supported by a DFG research fellowship (FI 2138/1-1) awarded to Roman Fischer.

Conflict of interest: John R. Bethea and Roman Fischer are named inventors on patent applications covering novel techniques for the treatment of neuropathic pain. 
Copyright and permission statement: To the best of our knowledge, the materials included in this chapter do not violate copyright laws. All original sources have been appropriately acknowledged and/or referenced. Where relevant, appropriate permissions have been obtained from the original copyright holder(s).

\section{References}

1. Woolf CJ, Bennett GJ, Doherty M, Dubner R, Kidd B, Koltzenburg M, et al. Towards a mechanism-based classification of pain? Pain. 1998;77(3):227-9. http://dx.doi.org/10.1016/S0304-3959(98)00099-2

2. Jensen TS, Baron R, Haanpaa M, Kalso E, Loeser JD, Rice AS, et al. A new definition of neuropathic pain. Pain. 2011;152(10):2204-5. http://dx.doi.org/10.1016/j.pain.2011.06.017

3. Vanderah TW. Pathophysiology of pain. Med Clin North Am. 2007;91(1):1-12. http://dx.doi. org/10.1016/j.mcna.2006.10.006

4. Fasick V, Spengler RN, Samankan S, Nader ND, Ignatowski TA. The hippocampus and TNF: Common links between chronic pain and depression. Neurosci Biobehav Rev. 2015;53:139-59. http://dx.doi. org/10.1016/j.neubiorev.2015.03.014

5. Mogil JS. Sex differences in pain and pain inhibition: Multiple explanations of a controversial phenomenon. Nat Rev Neurosci. 2012;13(12):859-66. http://dx.doi.org/10.1038/nrn3360

6. Torrance N, Ferguson JA, Afolabi E, Bennett MI, Serpell MG, Dunn KM, et al. Neuropathic pain in the community: More under-treated than refractory? Pain. 2013;154(5):690-9. http://dx.doi. org/10.1016/j.pain.2012.12.022

7. Finnerup NB, Attal N, Haroutounian S, McNicol E, Baron R, Dworkin RH, et al. Pharmacotherapy for neuropathic pain in adults: A systematic review and meta-analysis. Lancet Neurol. 2015;14(2):162-73. http://dx.doi.org/10.1016/S1474-4422(14)70251-0

8. O'Connor AB, Schwid SR, Herrmann DN, Markman JD, Dworkin RH. Pain associated with multiple sclerosis: Systematic review and proposed classification. Pain. 2008;137(1):96-111. http://dx.doi. org/10.1016/j.pain.2007.08.024

9. Bermejo PE, Oreja-Guevara C, Diez-Tejedor E. [Pain in multiple sclerosis: Prevalence, mechanisms, types and treatment]. Rev Neurol. 2010;50(2):101-8.

10. Ford B. Pain in Parkinson's disease. Mov Disord. 2010;25(Suppl 1):S98-103. http://dx.doi. org $/ 10.1002 / \mathrm{mds} .22716$

11. Simuni T, Sethi K. Nonmotor manifestations of Parkinson's disease. Ann Neurol. 2008;64(Suppl 2):S65-80. http://dx.doi.org/10.1002/ana.21472

12. Pautex S, Michon A, Guedira M, Emond H, Le Lous P, Samaras D, et al. Pain in severe dementia: Self-assessment or observational scales? J Am Geriatr Soc. 2006;54(7):1040-5. http://dx.doi. org/10.1111/j.1532-5415.2006.00766.x

13. Davies M, Brophy S, Williams R, Taylor A. The prevalence, severity, and impact of painful diabetic peripheral neuropathy in type 2 diabetes. Diabetes Care. 2006;29(7):1518-22. http://dx.doi. org/10.2337/dc05-2228

14. Lema MJ, Foley KM, Hausheer FH. Types and epidemiology of cancer-related neuropathic pain: The intersection of cancer pain and neuropathic pain. Oncologist. 2010;15(Suppl 2):3-8. http://dx.doi. org/10.1634/theoncologist.2009-S505

15. Fallon MT. Neuropathic pain in cancer. Br J Anaesth. 2013;111(1):105-11. http://dx.doi.org/10.1093/ bja/aet208

16. Gilron I, Baron R, Jensen T. Neuropathic pain: Principles of diagnosis and treatment. Mayo Clin Proc. 2015;90(4):532-45. http://dx.doi.org/10.1016/j.mayocp.2015.01.018

17. Truini A, Barbanti P, Pozzilli C, Cruccu G. A mechanism-based classification of pain in multiple sclerosis. J Neurol. 2013;260(2):351-67. http://dx.doi.org/10.1007/s00415-012-6579-2

18. Finnerup NB, Haroutounian S, Kamerman P, Baron R, Bennett DL, Bouhassira D, et al. Neuropathic pain: An updated grading system for research and clinical practice. Pain. 2016;157(8):1599-606. http://dx.doi.org/10.1097/j.pain.0000000000000492 
19. Baron R, Binder A, Wasner G. Neuropathic pain: Diagnosis, pathophysiological mechanisms, and treatment. Lancet Neurol. 2010;9(8):807-19. http://dx.doi.org/10.1016/S1474-4422(10)70143-5

20. Tian DH, Perera CJ, Moalem-Taylor G. Neuropathic pain in animal models of nervous system autoimmune diseases. Mediators Inflamm. 2013;2013:298326. http://dx.doi.org/10.1155/ $2013 / 298326$

21. Woolf CJ, Mannion RJ. Neuropathic pain: Aetiology, symptoms, mechanisms, and management. Lancet. 1999;353(9168):1959-64. http://dx.doi.org/10.1016/S0140-6736(99)01307-0

22. Dworkin RH, Backonja M, Rowbotham MC, Allen RR, Argoff CR, Bennett GJ, et al. Advances in neuropathic pain: Diagnosis, mechanisms, and treatment recommendations. Arch Neurol. 2003;60(11):1524-34. http://dx.doi.org/10.1001/archneur.60.11.1524

23. Ashburn MA, Staats PS. Management of chronic pain. Lancet. 1999;353(9167):1865-9. http://dx.doi. org/10.1016/S0140-6736(99)04088-X

24. Haythornthwaite JA, Benrud-Larson LM. Psychological aspects of neuropathic pain. Clin J Pain. 2000;16(2 Suppl):S101-5. http://dx.doi.org/10.1097/00002508-200006001-00017

25. Berkley KJ. Sex differences in pain. Behav Brain Sci. 1997;20(3):371-80; discussion 435-513. http:// dx.doi.org/10.1017/S0140525X97221485

26. Bouhassira D, Lanteri-Minet M, Attal N, Laurent B, Touboul C. Prevalence of chronic pain with neuropathic characteristics in the general population. Pain. 2008;136(3):380-7. http://dx.doi. org/10.1016/j.pain.2007.08.013

27. de Mos M, de Bruijn AG, Huygen FJ, Dieleman JP, Stricker BH, Sturkenboom MC. The incidence of complex regional pain syndrome: A population-based study. Pain. 2007;129(1-2):12-20. http:// dx.doi.org/10.1016/j.pain.2006.09.008

28. Briscoe ME. Why do people go to the doctor? Sex differences in the correlates of GP consultation. Soc Sci Med. 1987;25(5):507-13. http://dx.doi.org/10.1016/0277-9536(87)90174-2

29. Maletic V, Robinson M, Oakes T, Iyengar S, Ball SG, Russell J. Neurobiology of depression: An integrated view of key findings. Int J Clin Pract. 2007;61(12):2030-40. http://dx.doi. org/10.1111/j.1742-1241.2007.01602.x

30. Gureje O, Von Korff M, Simon GE, Gater R. Persistent pain and well-being: A World Health Organization Study in Primary Care. JAMA. 1998;280(2):147-51. http://dx.doi.org/10.1001/ jama.280.2.147

31. Sullivan MJ, Reesor K, Mikail S, Fisher R. The treatment of depression in chronic low back pain: Review and recommendations. Pain. 1992;50(1):5-13. http://dx.doi.org/10.1016/0304-3959(92)90107-M

32. Sansone RA, Sansone LA. Pain, pain, go away: Antidepressants and pain management. Psychiatry (Edgmont). 2008;5(12):16-19.

33. Compston A, Coles A. Multiple sclerosis. Lancet. 2008;372(9648):1502-17. http://dx.doi. org/10.1016/S0140-6736(08)61620-7

34. Khan N, Smith MT. Multiple sclerosis-induced neuropathic pain: Pharmacological management and pathophysiological insights from rodent EAE models. Inflammopharmacology. 2014;22(1):1-22. http://dx.doi.org/10.1007/s10787-013-0195-3

35. Svendsen KB, Jensen TS, Overvad K, Hansen HJ, Koch-Henriksen N, Bach FW. Pain in patients with multiple sclerosis: A population-based study. Arch Neurol. 2003;60(8):1089-94. http://dx.doi. org/10.1001/archneur.60.8.1089

36. Kalia LV, O'Connor PW. Severity of chronic pain and its relationship to quality of life in multiple sclerosis. Mult Scler. 2005;11(3):322-7. http://dx.doi.org/10.1191/1352458505msl168oa

37. Solaro C, Uccelli MM. Management of pain in multiple sclerosis: A pharmacological approach. Nat Rev Neurol. 2011;7(9):519-27. http://dx.doi.org/10.1038/nrneurol.2011.120

38. Toosy A, Ciccarelli O, Thompson A. Symptomatic treatment and management of multiple sclerosis. Handb Clin Neurol. 2014;122:513-62. http://dx.doi.org/10.1016/B978-0-444-52001-2.00023-6

39. Osterberg A, Boivie J. Central pain in multiple sclerosis-Sensory abnormalities. Eur J Pain. 2010;14(1):104-10. http://dx.doi.org/10.1016/j.ejpain.2009.03.003

40. Seixas D, Foley P, Palace J, Lima D, Ramos I, Tracey I. Pain in multiple sclerosis: A systematic review of neuroimaging studies. Neuroimage Clin. 2014;5:322-31. http://dx.doi.org/10.1016/j. nicl.2014.06.014 
41. Osterberg A, Boivie J, Thuomas KA. Central pain in multiple sclerosis-Prevalence and clinical characteristics. Eur J Pain. 2005;9(5):531-42. http://dx.doi.org/10.1016/j.ejpain.2004.11.005

42. Svendsen KB, Jensen TS, Hansen HJ, Bach FW. Sensory function and quality of life in patients with multiple sclerosis and pain. Pain. 2005;114(3):473-81. http://dx.doi.org/10.1016/j.pain.2005. 01.015

43. Thompson AJ, Toosy AT, Ciccarelli O. Pharmacological management of symptoms in multiple sclerosis: Current approaches and future directions. Lancet Neurol. 2010;9(12):1182-99. http://dx.doi. org/10.1016/S1474-4422(10)70249-0

44. Vacca G, Marano E, Brescia Morra V, Lanzillo R, De Vito M, Parente E, et al. Multiple sclerosis and headache co-morbidity. A case-control study. Neurol Sci. 2007;28(3):133-5. http://dx.doi.org/10.1007/ s10072-007-0805-1

45. Nurmikko TJ, Gupta S, Maclver K. Multiple sclerosis-related central pain disorders. Curr Pain Headache Rep. 2010;14(3):189-95. http://dx.doi.org/10.1007/s11916-010-0108-8

46. Truini A, Galeotti F, Cruccu G. Treating pain in multiple sclerosis. Expert Opin Pharmacother. 2011;12(15):2355-68. http://dx.doi.org/10.1517/14656566.2011.607162

47. Al-Araji AH, Oger J. Reappraisal of Lhermitte's sign in multiple sclerosis. Mult Scler. 2005;11(4):398402. http://dx.doi.org/10.1191/1352458505ms1177oa

48. Kanchandani R, Howe JG. Lhermitte's sign in multiple sclerosis: A clinical survey and review of the literature. J Neurol Neurosurg Psychiatry. 1982;45(4):308-12. http://dx.doi.org/10.1136/ jnnp.45.4.308

49. Montano N, Conforti G, Di Bonaventura R, Meglio M, Fernandez E, Papacci F. Advances in diagnosis and treatment of trigeminal neuralgia. Ther Clin Risk Manage. 2015;11:289-99. http://dx.doi. org/10.2147/TCRM.S37592

50. Solaro C, Brichetto G, Amato MP, Cocco E, Colombo B, D'Aleo G, et al. The prevalence of pain in multiple sclerosis: A multicenter cross-sectional study. Neurology. 2004;63(5):919-21. http://dx.doi. org/10.1212/01.WNL.0000137047.85868.D6

51. Nurmikko TJ. Pathophysiology of MS-related trigeminal neuralgia. Pain. 2009;143(3):165-6. http:// dx.doi.org/10.1016/j.pain.2009.03.019

52. Chen DQ, DeSouza DD, Hayes DJ, Davis KD, O'Connor P, Hodaie M. Diffusivity signatures characterize trigeminal neuralgia associated with multiple sclerosis. Mult Scler. 2016;22(1):51-63. http:// dx.doi.org/10.1177/1352458515579440

53. Moulin DE, Foley KM, Ebers GC. Pain syndromes in multiple sclerosis. Neurology. 1988;38(12):1830_4. http://dx.doi.org/10.1212/WNL.38.12.1830

54. Archibald CJ, McGrath PJ, Ritvo PG, Fisk JD, Bhan V, Maxner CE, et al. Pain prevalence, severity and impact in a clinic sample of multiple sclerosis patients. Pain. 1994;58(1):89-93. http://dx.doi. org/10.1016/0304-3959(94)90188-0

55. Stenager E, Knudsen L, Jensen K. Acute and chronic pain syndromes in multiple sclerosis. Acta Neurol Scand. 1991;84(3):197-200. http://dx.doi.org/10.1111/j.1600-0404.1991.tb04937.x

56. Schreiner B, Heppner FL, Becher B. Modeling multiple sclerosis in laboratory animals. Semin Immunopathol. 2009;31(4):479-95. http://dx.doi.org/10.1007/s00281-009-0181-4

57. Olechowski CJ, Truong JJ, Kerr BJ. Neuropathic pain behaviours in a chronic-relapsing model of experimental autoimmune encephalomyelitis (EAE). Pain. 2009;141(1-2):156-64. http://dx.doi. org/10.1016/j.pain.2008.11.002

58. Storch MK, Stefferl A, Brehm U, Weissert R, Wallstrom E, Kerschensteiner M, et al. Autoimmunity to myelin oligodendrocyte glycoprotein in rats mimics the spectrum of multiple sclerosis pathology. Brain Pathol. 1998;8(4):681-94. http://dx.doi.org/10.1111/j.1750-3639.1998.tb00194.x

59. Gritsch S, Lu J, Thilemann S, Wortge S, Mobius W, Bruttger J, et al. Oligodendrocyte ablation triggers central pain independently of innate or adaptive immune responses in mice. Nat Commun. 2014:5:5472. http://dx.doi.org/10.1038/ncomms6472

60. Scholz J, Woolf CJ. The neuropathic pain triad: Neurons, immune cells and glia. Nat Neurosci. 2007;10(11):1361-8. http://dx.doi.org/10.1038/nn1992

61. Zhang JM, An J. Cytokines, inflammation, and pain. Int Anesthesiol Clin. 2007;45(2):27-37. http:// dx.doi.org/10.1097/AIA.0b013e318034194e 
62. Sloane E, Ledeboer A, Seibert W, Coats B, van Strien M, Maier SF, et al. Anti-inflammatory cytokine gene therapy decreases sensory and motor dysfunction in experimental Multiple Sclerosis: MOGEAE behavioral and anatomical symptom treatment with cytokine gene therapy. Brain Behav Immun. 2009;23(1):92-100. http://dx.doi.org/10.1016/j.bbi.2008.09.004

63. Dworkin RH, O'Connor AB, Audette J, Baron R, Gourlay GK, Haanpaa ML, et al. Recommendations for the pharmacological management of neuropathic pain: An overview and literature update. Mayo Clin Proc. 2010;85(3 Suppl):S3-14. http://dx.doi.org/10.4065/mcp.2009.0649

64. Dworkin RH, O'Connor AB, Backonja M, Farrar JT, Finnerup NB, Jensen TS, et al. Pharmacologic management of neuropathic pain: Evidence-based recommendations. Pain. 2007;132(3):237-51. http://dx.doi.org/10.1016/j.pain.2007.08.033

65. Jackson KC 2nd, St Onge EL. Antidepressant pharmacotherapy: Considerations for the pain clinician. Pain Pract. 2003;3(2):135-43. http://dx.doi.org/10.1046/j.1533-2500.2003.03020.x

66. Gillman PK. Tricyclic antidepressant pharmacology and therapeutic drug interactions updated. Br J Pharmacol. 2007;151(6):737-48. http://dx.doi.org/10.1038/sj.bjp.0707253

67. Colombo B, Annovazzi PO, Comi G. Medications for neuropathic pain: Current trends. Neurol Sci. 2006;27(Suppl 2):S183-9. http://dx.doi.org/10.1007/s10072-006-0598-7

68. Vranken JH, Hollmann MW, van der Vegt MH, Kruis MR, Heesen M, Vos K, et al. Duloxetine in patients with central neuropathic pain caused by spinal cord injury or stroke: A randomized, double-blind, placebo-controlled trial. Pain. 2011;152(2):267-73. http://dx.doi.org/10.1016/j.pain. 2010.09.005

69. Cianchetti C, Zuddas A, Randazzo AP, Perra L, Marrosu MG. Lamotrigine adjunctive therapy in painful phenomena in MS: Preliminary observations. Neurology. 1999;53(2):433. http://dx.doi.org/10.1212/ WNL.53.2.433

70. Falah M, Madsen C, Holbech JV, Sindrup SH. A randomized, placebo-controlled trial of levetiracetam in central pain in multiple sclerosis. Eur J Pain. 2012;16(6):860-9. http://dx.doi. org/10.1002/j.1532-2149.2011.00073.x

71. Solaro C, Brichetto G, Battaglia MA, Messmer Uccelli M, Mancardi GL. Antiepileptic medications in multiple sclerosis: Adverse effects in a three-year follow-up study. Neurol Sci. 2005;25(6):307-10. http://dx.doi.org/10.1007/s10072-004-0362-9

72. Solaro C, Restivo D, Mancardi GL, Tanganelli P. Oxcarbazepine for treating paroxysmal painful symptoms in multiple sclerosis: A pilot study. Neurol Sci. 2007;28(3):156-8. http://dx.doi.org/10.1007/ s10072-007-0811-3

73. Sakurai M, Kanazawa I. Positive symptoms in multiple sclerosis: Their treatment with sodium channel blockers, lidocaine and mexiletine. J Neurol Sci. 1999;162(2):162-8. http://dx.doi.org/10.1016/ S0022-510X(98)00322-0

74. Rice AS. Should cannabinoids be used as analgesics for neuropathic pain? Nat Clin Pract Neurol. 2008;4(12):654-5. http://dx.doi.org/10.1038/ncpneuro0949

75. Svendsen KB, Jensen TS, Bach FW. Does the cannabinoid dronabinol reduce central pain in multiple sclerosis? Randomised double blind placebo controlled crossover trial. BMJ. 2004;329(7460):253. http://dx.doi.org/10.1136/bmj.38149.566979.AE

76. Cruccu G, Aziz TZ, Garcia-Larrea L, Hansson P, Jensen TS, Lefaucheur JP, et al. EFNS guidelines on neurostimulation therapy for neuropathic pain. Eur J Neurol. 2007;14(9):952-70. http://dx.doi. org/10.1111/j.1468-1331.2007.01916.x

77. Provenzano DA, Williams JR, Jarzabek G, DeRiggi LA, Scott TF. Treatment of neuropathic pain and functional limitations associated with multiple sclerosis using an MRI-compatible spinal cord stimulator: A case report with two year follow-up and literature review. Neuromodulation. 2016;19(4):406-13. http://dx.doi.org/10.1111/ner. 12409

78. Yakhnitsa V, Linderoth B, Meyerson BA. Spinal cord stimulation attenuates dorsal horn neuronal hyperexcitability in a rat model of mononeuropathy. Pain. 1999;79(2-3):223-33. http://dx.doi. org/10.1016/S0304-3959(98)00169-9

79. Geranton SM, Jimenez-Diaz L, Torsney C, Tochiki KK, Stuart SA, Leith JL, et al. A rapamycinsensitive signaling pathway is essential for the full expression of persistent pain states. J Neurosci. 2009;29(47):15017-27. http://dx.doi.org/10.1523/JNEUROSCI.3451-09.2009 
80. Lisi L, Navarra P, Cirocchi R, Sharp A, Stigliano E, Feinstein DL, et al. Rapamycin reduces clinical signs and neuropathic pain in a chronic model of experimental autoimmune encephalomyelitis. J Neuroimmunol. 2012;243(1-2):43-51. http://dx.doi.org/10.1016/j.jneuroim.2011.12.018

81. Esposito M, Ruffini F, Bellone M, Gagliani N, Battaglia M, Martino G, et al. Rapamycin inhibits relapsing experimental autoimmune encephalomyelitis by both effector and regulatory $\mathrm{T}$ cells modulation. J Neuroimmunol. 2010;220(1-2):52-63. http://dx.doi.org/10.1016/j.jneuroim.2010.01.001

82. Cohen JA, Barkhof F, Comi G, Hartung HP, Khatri BO, Montalban X, et al. Oral fingolimod or intramuscular interferon for relapsing multiple sclerosis. N Engl J Med. 2010;362(5):402-15. http:// dx.doi.org/10.1056/NEJMoa0907839

83. Coste O, Pierre S, Marian C, Brenneis C, Angioni C, Schmidt H, et al. Antinociceptive activity of the S1P-receptor agonist FTY720. J Cell Mol Med. 2008;12(3):995-1004. http://dx.doi. org/10.1111/j.1582-4934.2008.00160.x

84. Collins S, Sigtermans MJ, Dahan A, Zuurmond WW, Perez RS. NMDA receptor antagonists for the treatment of neuropathic pain. Pain Med. 2010;11(11):1726-42. http://dx.doi. org/10.1111/j.1526-4637.2010.00981.x

85. Srinivasan R, Sailasuta N, Hurd R, Nelson S, Pelletier D. Evidence of elevated glutamate in multiple sclerosis using magnetic resonance spectroscopy at 3 T. Brain. 2005;128(Pt 5):1016-25. http://dx.doi. org/10.1093/brain/awh467

86. Vallejo-Illarramendi A, Domercq M, Perez-Cerda F, Ravid R, Matute C. Increased expression and function of glutamate transporters in multiple sclerosis. Neurobiol Dis. 2006;21(1):154-64. http://dx.doi. org/10.1016/j.nbd.2005.06.017

87. Basso AS, Frenkel D, Quintana FJ, Costa-Pinto FA, Petrovic-Stojkovic S, Puckett L, et al. Reversal of axonal loss and disability in a mouse model of progressive multiple sclerosis. J Clin Invest. 2008;118(4):1532-43. http://dx.doi.org/10.1172/JCI33464

88. Olechowski CJ, Parmar A, Miller B, Stephan J, Tenorio G, Tran K, et al. A diminished response to formalin stimulation reveals a role for the glutamate transporters in the altered pain sensitivity of mice with experimental autoimmune encephalomyelitis (EAE). Pain. 2010;149(3):565-72. http://dx.doi. org/10.1016/j.pain.2010.03.037 